
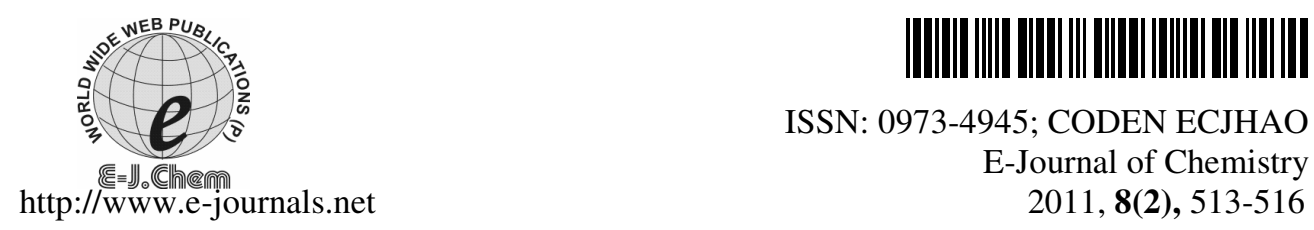

ISSN: 0973-4945; CODEN ECJHAO

E-Journal of Chemistry

2011, 8(2), 513-516

\title{
Thermal Decomposition Kinetics of Labile Chromium Complex with Benzoic Acid
}

\author{
M.K.MISHRA* and N.M.MISRA \\ *Department of Chemistry B.I.T., Sindri, Dhanbad, India \\ Department of Applied Chemistry ISM, Dhanbad, India \\ mkmishrabit@gmail.com
}

Received 6 June 2010; Accepted 2 August 2010

\begin{abstract}
Complex $\left[\mathrm{CrO}_{2}\left(\mathrm{C}_{7} \mathrm{H}_{5} \mathrm{O}_{2}\right)\left(\mathrm{C}_{2} \mathrm{H}_{5} \mathrm{OH}\right)\left(\mathrm{H}_{2} \mathrm{O}\right)_{2}\right]$ was prepared by using benzoic acid. Its spectral characterization was done by using Elemental analysis ( $\mathrm{C}$ and $\mathrm{H}$ ), Inductively coupled plasma optical emission spectroscopy (ICP - OES), Ultraviolet - visible (UV-Vis) spectroscopy, Fourier transform infrared (FTIR) spectroscopy and Fast Atomic Bombardment (FAB) Mass spectrometry. Whereas thermal decomposition was investigated by differential scanning calorimetric (DSC). The low value of activation energy of exothermic change indicated lability of complex.
\end{abstract}

Keywords: Labile, Chromium complexes, Thermal decomposition kinetics, Energetic materials, Benzoic acid

\section{Introduction}

Chromium metal has played a prominent role in the development of inorganic chemistry. Chromium trioxide reacts vigorously with organic substances; is widely used as an oxidant in synthetic organic chemistry ${ }^{1-3}$. Complexation reactions with organic ligands produce coordination compounds / complexes with differing degree of thermodynamic stability and lability ${ }^{4-7}$. It has been reported that the covalent coordinate bond having energy $20-80 \mathrm{kcal} / \mathrm{mol}$ with first row metal ligand bond show high stability and high lability ${ }^{8-9}$. A rapid reaction rate has been observed between $\mathrm{Cr}$ (III)-Schiff's base complexes and nicotinic acid and there are also some other systems such as porphyrin complexes with similar labile kinetic behavior ${ }^{10-13}$. Chromium(III) octahedral complexes are generally inert to the substitution of inner sphere water molecules by other ligands but some report indicate, however, the chromium(III) complexes, Aqua (ethylenediaminetriaaceto acetic acid) chromium(III), with one molecule of water and a five coordinate EDTA type ligand shows unexpectedly rapid substitution rates with several anionic ligands. It has been suggested that these reactions are due in part to strain present in the complex ${ }^{14}$.

In the present investigation, we have studied on the synthesis and characterization of chromium metal complex using benzoic acid as the ligand. Thermal behavior of this complex has also been investigated to understand the thermodynamic stability and lability of this complex. 


\section{Experimental}

Benzoic acid (E.Merck), chromic acid $\mathrm{CrO}_{3}$ (Apex chemicals) and ethyl alcohol (Merck$\mathrm{KgaA}$ ) were used as received. The elemental microanalysis of $\mathrm{C}$ and $\mathrm{H}$ were carried out with a Thomas and Coleman Analyzer-Carlo Erba1106 while the metal content in the complex was determined by Perkin Elmer 5300DV(Duel View), IR spectra was recorded on a perkinElmer 1600 series FTIR spectrometer in KBr pellets. The FAB Mass spectrum was recorded on Jeol SX - 102 (FAB) Mass spectrometer. DSC studies was carried out Perkin Elmer's DSC-7, Scan rate: $50{ }^{\circ} \mathrm{C}$.

$1.22 \mathrm{~g}$ of Benzoic acid was dissolved in $100 \mathrm{~mL}$ of ethyl alcohol and $1 \mathrm{~g}$ of $\mathrm{CrO}_{3}$ was dissolved in $40 \mathrm{~mL}$ of water. A solution of benzoic acid was slowly added with stirring to a solution of $\mathrm{CrO}_{3}$. The resulting solution was refluxed for $30 \mathrm{~min}$. The yellowish-green colored compound formed was separated by filtration. It was washed with $40 \%$ ethanol and dried in air. Yield $1.00 \mathrm{~g}(45 \%)$.

\section{Results and Discussion}

Elemental ( $\mathrm{C}$ and $\mathrm{H} \%$ ) and ICP-OES analysis: The chromium-benzoic acid complexes (MRBT1) formed was colored insoluble in water and common organic solvent, but was found to be soluble in DMSO at room temperature. Analytical data found (Calcd.\%) for $\mathrm{C}_{9} \mathrm{H}_{15} \mathrm{CrO}_{7} ; \mathrm{C}, 38.74(37.63) ; \mathrm{H}, 4.96(5.23) ; \mathrm{Cr}, 19.14(18.12)$

UV-Visible spectra of complex (Figure 1) shows two bands in the ranges of 470-500 and 525-560 $\mathrm{nm}$ which can be assigned respectively to ${ }^{4} \mathrm{~A}_{2} \mathrm{~g} \rightarrow{ }^{4} \mathrm{Tig}$ and ${ }^{4} \mathrm{~A} 2 \mathrm{~g} \rightarrow{ }^{4} \mathrm{~T}_{2} \mathrm{~g} d-d$ transitions of octahedral chromium complexes ${ }^{15-16}$.

\section{Electronic spectra}

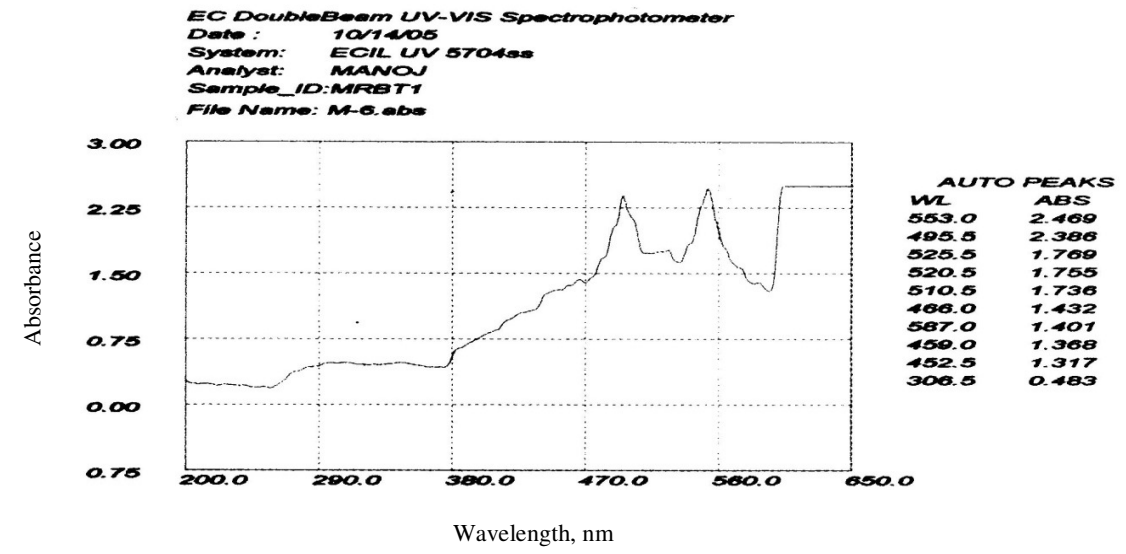

Figure 1. UV-Vis spectrum of MRBT1

The characteristic absorption peak of FTIR (Figure 2) at $1680 \mathrm{~cm}^{-1}$ and $1289 \mathrm{~cm}^{-1}$ is attributed to $\mathrm{C}=\mathrm{O}$ of and $\mathrm{C}-\mathrm{O}$ stretching frequency of carboxyl group of benzoic acid respectively. The broad band $2361 \mathrm{~cm}^{-1}$ is due to the hydrogen bonded $v(\mathrm{O}-\mathrm{H})$ stretching vibration. Other vibrational frequency at $1420 \mathrm{~cm}^{-1}$ and $1526 \mathrm{~cm}^{-1}$ are assigned to $v(\mathrm{C}-\mathrm{H}) \&$ $v(\mathrm{C}=\mathrm{H})$ of aromatic ring respectively. Appearance of new bands in the region $600-700 \mathrm{~cm}^{-1}$ in the spectra of complex are attributed to $v(\mathrm{Cr}-\mathrm{O})$ as seen in the spectra of metal complexes suggest that the product has been formed. Some weak bending modes are also observed at $1026 \mathrm{~cm}^{-1}$ due to $(\mathrm{OCO})$ and $718 \mathrm{~cm}^{-1}$ due to $(\mathrm{OCO})^{17}$. 


\section{The FAB mass spectra}

MRBT1: $\left[\mathrm{CrO}_{2}\left(\mathrm{C}_{7} \mathrm{H}_{5} \mathrm{O}_{2}\right)\left(\mathrm{C}_{2} \mathrm{H}_{5} \mathrm{OH}\right)\left(\mathrm{H}_{2} \mathrm{O}\right)_{2}\right]$. Anal.: found $\mathrm{C}, 38.74 ; \mathrm{H}, 4.96 ; \mathrm{Cr}, 19.14$ Calcd. For $\mathrm{C}_{9} \mathrm{H}_{15} \mathrm{Cr} \mathrm{O}_{7}$ : C, 37.63; H, 5.23; Cr, 18.12. Calculated mol. wt. of the complex: 287; Observed Molecular Ion Peak $(\mathrm{m} / \mathrm{z})$ : 252. The difference in molecular weight may correspond to the loss of two molecules of water.

The results from FAB Mass spectra as shown in Figure 3, were inferred on the basis as followed by Baranwal et $a l^{18}$ on oxo-bridge multinuclear chromium assemblies like trinuclear complex $\left[\mathrm{Cr}_{3} \mathrm{O}(\mathrm{acac})_{3}\left(\mathrm{OCCC}_{15} \mathrm{H}_{31}\right)_{3}\right]^{18}$. The $\mathrm{FAB}$ mass data of complex MRBT1are given in Table 1.

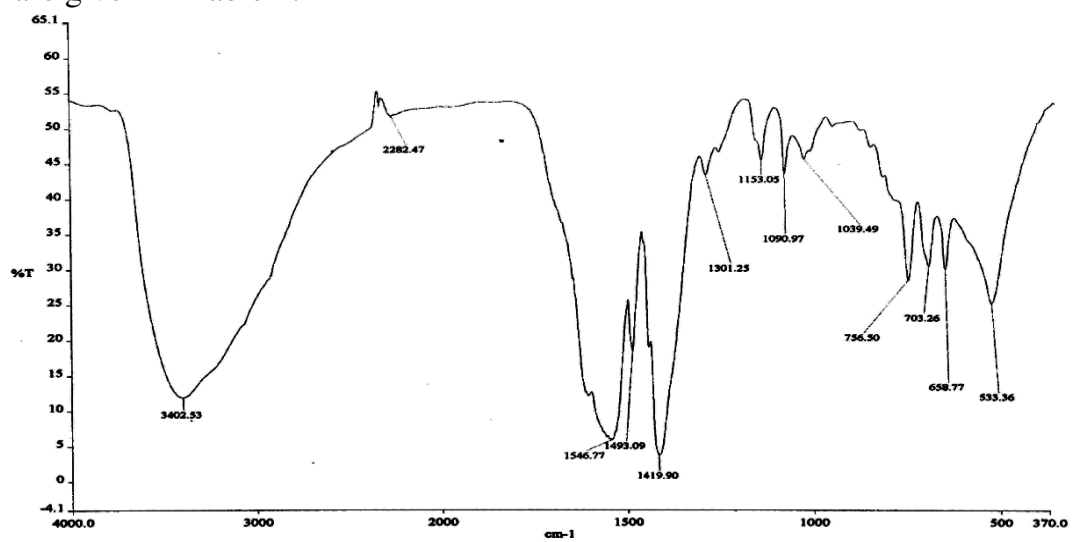

Figure 2. FTIR spectrum of the complex

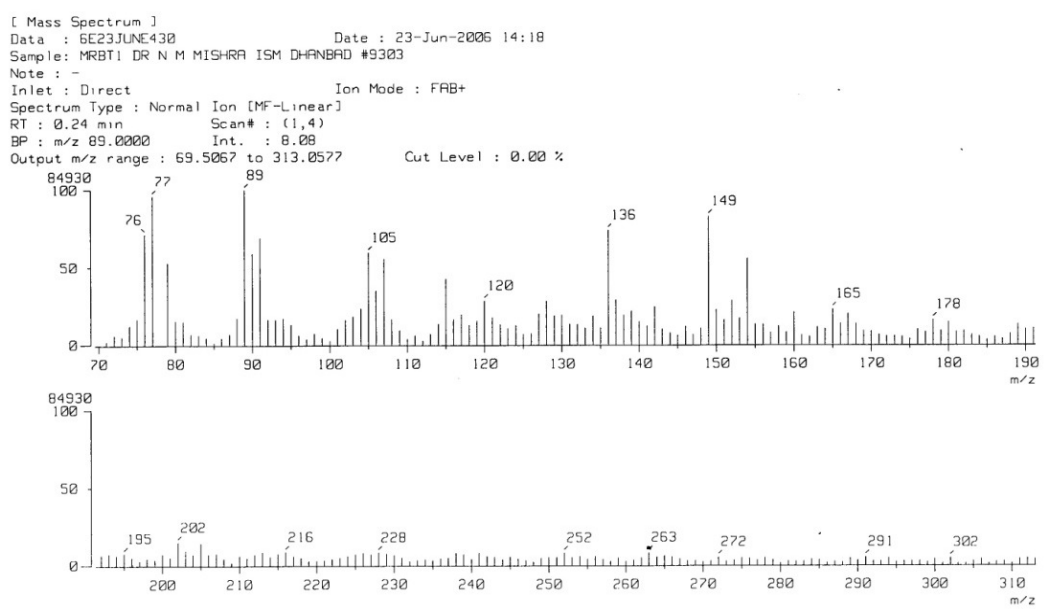

Figure 3.FAB Mass spectrum of the complex

\section{DSC analysis}

The values of kinetic parameters - enthalpy $(\Delta \mathrm{H})$, activation energy $(\mathrm{Ea}), \ln \mathrm{k}_{\mathrm{o}}$ and order of reaction $(\mathrm{n})$ were obtained by DSC thermogram for the dehydration and decomposition of the dehydrated complexes. In complex, low value of activation energy of the exothermic change indicated lability of the complex. Comparing kinetic parameters of chromiumbenzoic acid complex (decomposition temperature $162-253{ }^{\circ} \mathrm{C}$, activation energy $64.73 \mathrm{~kJ} / \mathrm{mole}$ ) with the kinetic parameter of some common energetic materials like, match stick 
(decomposition temperture $175-280{ }^{0} \mathrm{C}$ activation energy $25-83 \mathrm{kcal} / \mathrm{mole}$ ), ammonium persulphate (decomposition temperature $275-355{ }^{\circ} \mathrm{C}$ activation energy $25-83 \mathrm{kcal} / \mathrm{mole}$ ), Pyrotechnique chocolate bomb (decomposition temperature $645-665{ }^{\circ} \mathrm{C}$, activation energy $75.38 \mathrm{kcal} / \mathrm{mole}$ ), gun powder (decomposition temperature $280-430{ }^{0} \mathrm{C}$, activation energy $24.05 \mathrm{kcal} / \mathrm{mole}$ ), it could be inferred that the most of the chromium-benzoic acid complex prepared can be considered as energetic materials ${ }^{19}$.

Table 1. FAB mass data of complex MRBT1

\begin{tabular}{clc}
\hline Peak position & Expected fragmentation species & Calculated mass \\
\hline 252 & $\mathrm{CrO}_{2}\left(\mathrm{C}_{7} \mathrm{H}_{5} \mathrm{O}_{2}\right)\left(\mathrm{C}_{2} \mathrm{H}_{5} \mathrm{OH}\right)$ & 251 \\
216 & $\mathrm{Cr}\left(\mathrm{C}_{7} \mathrm{H}_{5} \mathrm{O}_{2}\right)\left(\mathrm{C}_{2} \mathrm{H}_{5} \mathrm{OH}\right)$ & 219 \\
202 & $\mathrm{Cr}\left(\mathrm{C}_{7} \mathrm{H}_{5} \mathrm{O}_{2}\right)\left(\mathrm{C}_{2} \mathrm{H}_{5}\right)$ & 202 \\
178 & $\left.\mathrm{Cr}_{5_{7}} \mathrm{C}_{7} \mathrm{H}_{5} \mathrm{O}_{2}\right)$ & 173 \\
120 & $\left(\mathrm{C}_{7} \mathrm{H}_{5} \mathrm{O}_{2}\right)$ & 121 \\
105 & $\left(\mathrm{COC}_{6} \mathrm{H}_{5}\right)$ & 105 \\
89 & $\left(\mathrm{CC}_{6} \mathrm{H}_{5}\right)$ & 89 \\
77 & $\left(\mathrm{C}_{6} \mathrm{H}_{5}\right)$ & 77 \\
\hline
\end{tabular}

\section{Conclusion}

Chromium complex i.e. $\left[\mathrm{CrO}_{2}\left(\mathrm{C}_{7} \mathrm{H}_{5} \mathrm{O}_{2}\right)\left(\mathrm{C}_{2} \mathrm{H}_{5} \mathrm{OH}\right)\left(\mathrm{H}_{2} \mathrm{O}\right)_{2}\right]$ was prepared by using benzoic acid. The low value of activation energy of the exothermic change indicated the lability of the complex. Thus the kinetics and lability of the complex could be predicted from the DSC. It was observed that the complexes formed could be used as energetic material.

\section{References}

1. Ellis J E, Hentges S G, Kalina D G and Hagen G P, J Organomet Chem., 1975, 97, 79-93.

2. Rollinson C L, The Chemistry of Chromium, Molybdenum and Tungsten, Pergamon Press, 1973.

3. Wiberg K B, Oxidation by Chromic Acid and Chromyl Compounds, Part 4, Academic Press, New York, 1965.

4. Taube H, Chem Rev., 1952, 50(1), 59.

5. Lay P A and Levina A, J Am Chem Soc., 1998, 120, 6704-6714.

6. Templeton D M, Ariese F, Cornelis R, Danielsson, Lars-Goran, Muntau H, Van Leeuwen H P, Ryszard and Lobinski, Pure Appl Chem., 2000, 72, 1453-1470.

7. Signorella S, Quiros M, Palopoli C, Brondino C, Salas Peregrin J M, Quiros M and Sala L F, Polyhedron, 1998, 17, 2739-2749.

8. Rollinson L, The Chemistry of Chromium, Molybdenum and Tungsten, Pergamon Press, 1973, pp 639-700

9. Goshe A J, Steele Ian M, Ceccarelli C; Rheingold A L and Bosnich B, PNAS, 2002, 99(8), 4823-4829.

10. Ramasami T, Wharton R K and Sykes A G, Inorg Chem., 1975, 14, 359.

11. Krishnamoorthy C.R and Harris G M, J Coord Chem., 1980, 10, 55.

12. Anis S S, Mat Chem Phys., 2001, 72(1), 88-92.

13. Yormah T B R, Fode DV A and Kormoh M K, AJST, 2002, 3(1), 108-112.

14. Gerdom L E; Baenziger N A and Goff H.M, Inorg Chem., 1981, 20, 1606-1609.

15. Arenas J F and Marcos J I, Spectrochim Acta Part A, 1980, 36, 1075.

16. Karmoh M K, Afr J Sci Tech., 1995, B7(2), 74-76.

17. Bellamy L J, The Infrared Spectrum of Complex Molecules, Third Ed., Chapman and Hall Ltd, London, 1975.

18. Baranwal B P and Fatma T, J Mol Struct., 2005, 750, 75.

19. Mishra M K, Mishra N M, Singh R K and Mishra R, J Inst Chemists( India), 2005, 77, 173-177. 


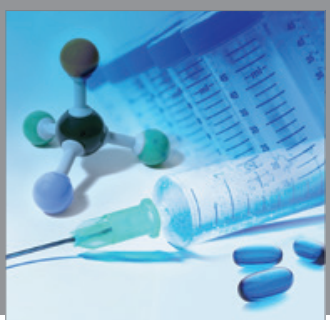

International Journal of

Medicinal Chemistry

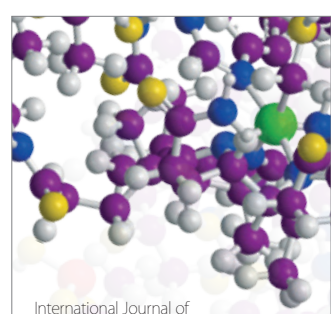

Carbohydrate Chemistry

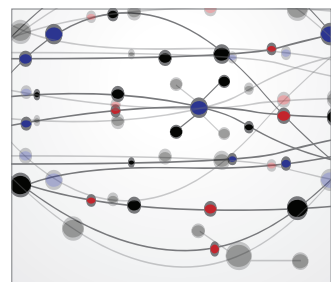

The Scientific World Journal
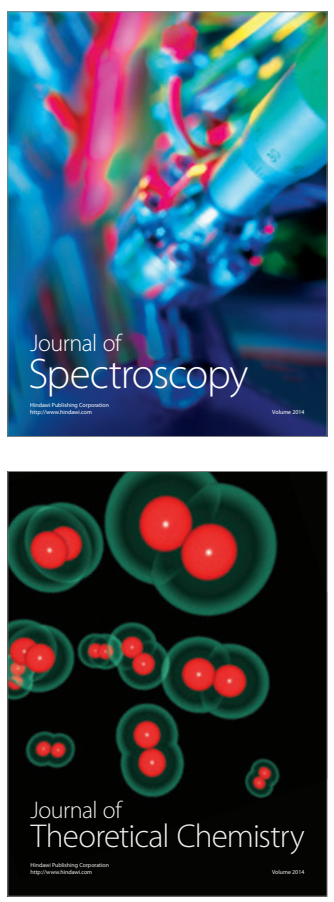
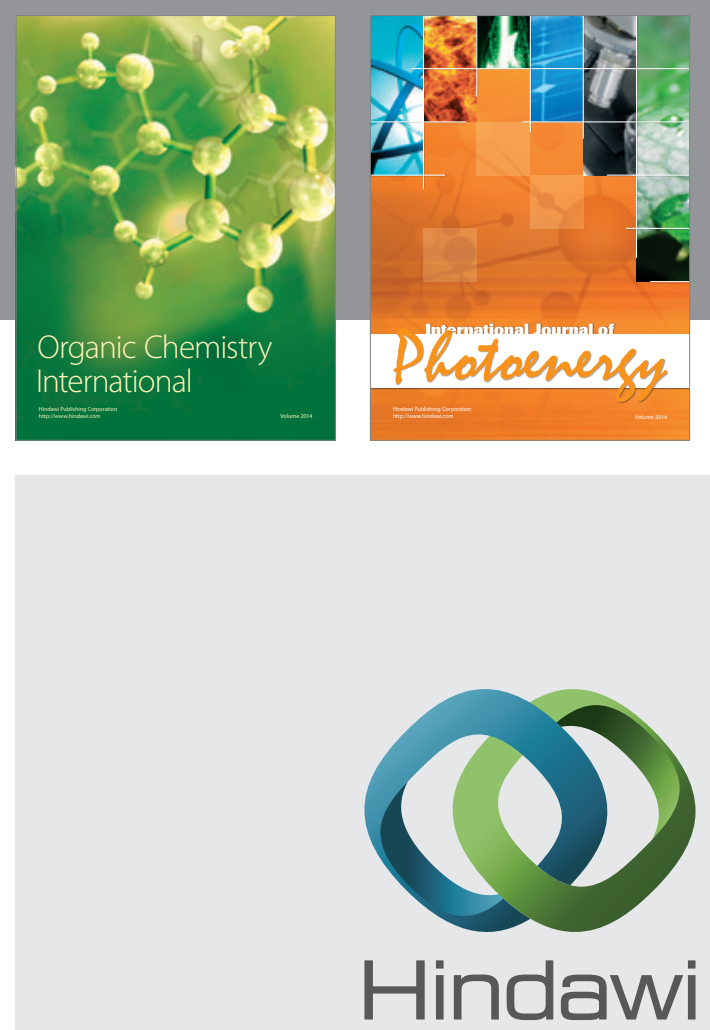

Submit your manuscripts at

http://www.hindawi.com
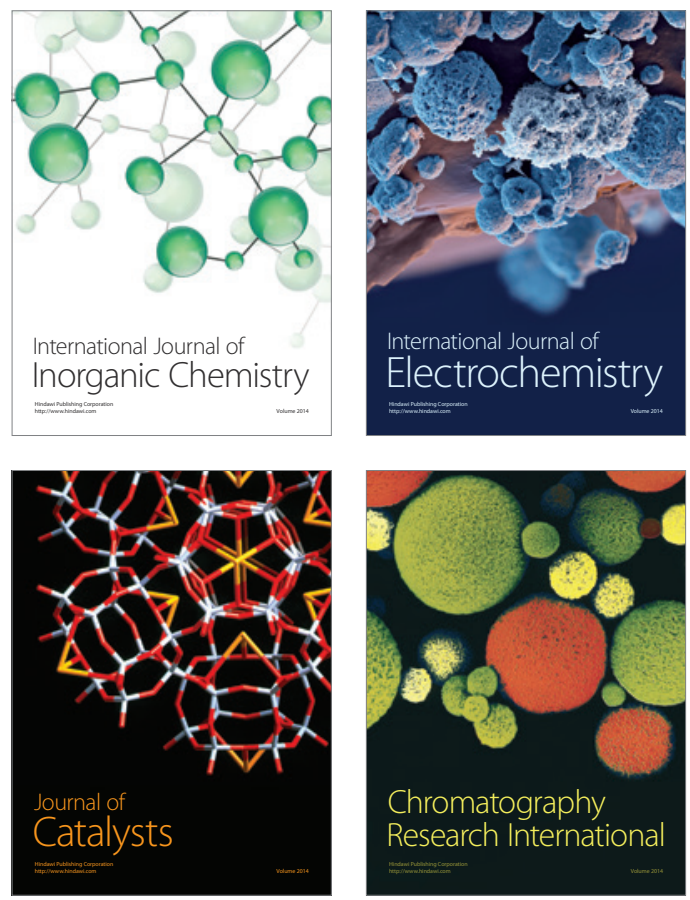
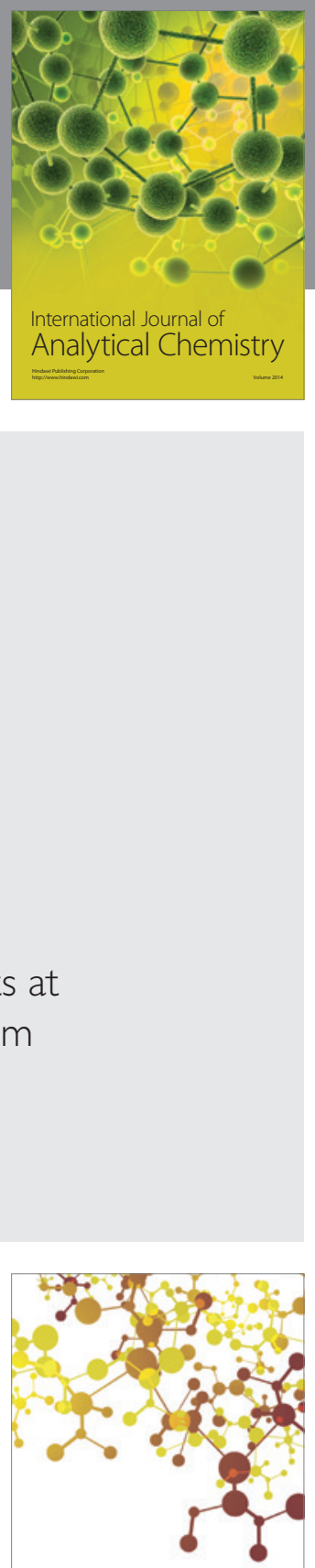

Journal of

Applied Chemistry
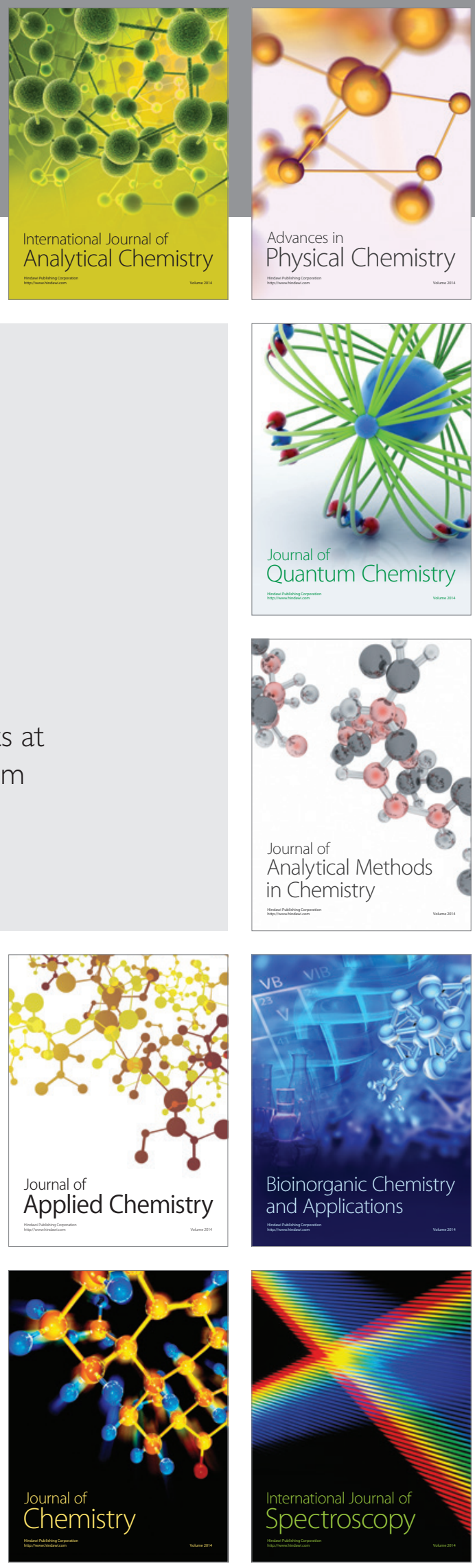